\title{
Long-term patient observation after conservative treatment of carpal tunnel syndrome: a summary of two randomised controlled trials
}

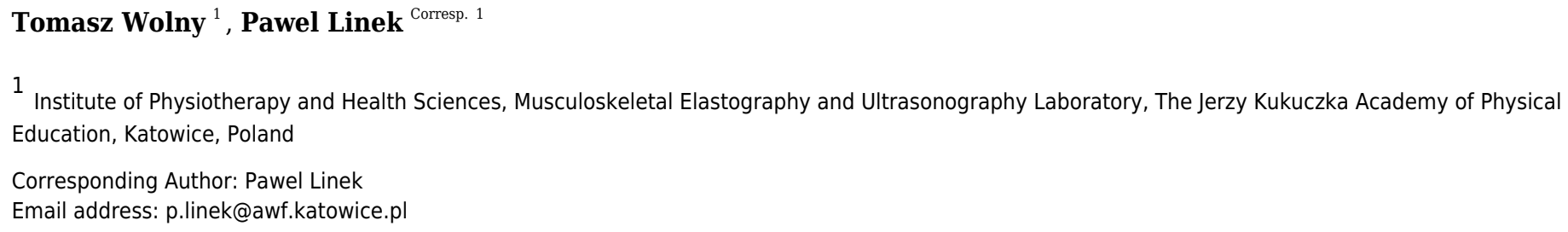

Background Physiotherapy of carpal tunnel syndrome (CTS) involves manual therapy based on neurodynamic techniques. Until now, two randomized controlled trials have shown that immediately after therapy, CTS patients who received neurodynamic techniques had significant improvement in nerve conduction, pain, symptom severity (SSS), functional state (FSS), muscle strength (MS) and two-point discrimination (2PD). However, long-term effects seem to be more important, as they are the only ones that can significantly improve the patient' health and influence economic and social costs. Thus, the objective of this study was to evaluate the long-term (six months) effects of neurodynamic techniques in the conservative treatment of CTS patients. Methods Carpal tunnel syndrome patients (107) from two previously published randomised clinical trials were observed for six months after the treatment based on neurodynamic techniques. Results The sensory conduction velocity, motor conduction velocity, and motor latency were not subject to statistically significant changes within six months after therapy ( $p>$ $0.05)$. In both groups, there was further pain reduction $(p<0.05)$. In group $B$, the symptom severity improved significantly $(p<0.05)$, while the functional status in both groups remained unchanged ( $p>0.05$ ). In both groups, there was muscle strenght improvement $(p<0.05)$. Two-point discrimination remained unchanged six months after the therapy. Conclusion The use of manual therapy based on neurodynamic techniques maintains the beneficial effects 6 months after therapy in CTS patients. 


\section{Long-term patient observation after conservative treatment}

\section{2 of carpal tunnel syndrome: a summary of two randomised}

\section{3 controlled trials}

4

5 PhD, PT Tomasz Wolny ${ }^{1}$; PhD, PT Pawel Linek ${ }^{1}$

6

7 Institute of Physiotherapy and Health Sciences, Musculoskeletal Elastography and

8 Ultrasonography Laboratory, The Jerzy Kukuczka Academy of Physical Education, Katowice,

9 Poland

Correspondence (for review and Publication)

\begin{tabular}{|l|l|}
\hline Name & Linek Pawel \\
\hline Department & $\begin{array}{l}\text { Institute of Physiotherapy and Health Sciences, Musculoskeletal Elastography } \\
\text { and Ultrasonography Laboratory }\end{array}$ \\
\hline Institution & $\begin{array}{l}\text { The Jerzy Kukuczka Academy of Physical Education, 40-065, Mikolowska } \\
\text { 72B }\end{array}$ \\
\hline Country & POLAND \\
\hline Tel & +48661768601 \\
\hline Mob & \\
\hline Fax & \\
\hline Email & p.linek@awf.katowice.pl \\
\hline
\end{tabular}

13 
27 Abstract

28 Background

29 Physiotherapy of carpal tunnel syndrome (CTS) involves manual therapy based on 30 neurodynamic techniques. Until now, two randomized controlled trials have shown that 31 immediately after therapy, CTS patients who received neurodynamic techniques had significant 32 improvement in nerve conduction, pain, symptom severity (SSS), functional state (FSS), muscle 33 strength (MS) and two-point discrimination (2PD). However, long-term effects seem to be more 34 important, as they are the only ones that can significantly improve the patient' health and 35 influence economic and social costs. Thus, the objective of this study was to evaluate the long36 term (six months) effects of neurodynamic techniques in the conservative treatment of CTS 37 patients.

\section{Methods}

39 Carpal tunnel syndrome patients (107) from two previously published randomised clinical trials 40 were observed for six months after the treatment based on neurodynamic techniques.

\section{Results}

42 The sensory conduction velocity, motor conduction velocity, and motor latency were not subject to statistically significant changes within six months after therapy $(p>0.05)$. In both groups,

44 there was further pain reduction $(\mathrm{p}<0.05)$. In group $\mathrm{B}$, the symptom severity improved 45 significantly $(\mathrm{p}<0.05)$, while the functional status in both groups remained unchanged $(\mathrm{p}>$ 46 0.05). In both groups, there was muscle strenght improvement $(\mathrm{p}<0.05)$. Two-point 47 discrimination remained unchanged six months after the therapy.

\section{Conclusion}

49 The use of manual therapy based on neurodynamic techniques maintains the beneficial effects 6 50 months after therapy in CTS patients. 


\section{Introduction}

55 Carpal tunnel syndrome (CTS) is the most common peripheral neuropathy (Aroori \&

56 Spence, 2008; Biernawska et al., 2005). In the initial period of the disease, there are temporary

57 subjective symptoms (i.e., pain, night-time paraesthesia, numbness, and tingling in the area of

58 the medial nerve innervation), which escalate with time. Then, the disorders of various types of

59 sensation develop, and in acute forms, there is impairment of the motor function of the hand

60 (Wolny et al., 2015; Wolny et al., 2016; Chang et al. 2008). This leads to a reduction in the

61 mobility of the hand, which can adversely affect working life, daily activities and overall health

62 (Wolny et al., 2016; Chang et al. 2008; Wolny et al., 2017). Thiese et al. (Thiese et al., 2014)

63 report that the incidence of CTS ranges from $6.3 \%$ to $11.7 \%$ and the occurrence of CTS is

64 considered to be epidemic (Thore et al., 2007). CTS is also common in the working age

65 (Newington et al., 2015), which is directly connected with significant health- care costs and

66 economic burden that are associated with lower productivity. The median of lost work time

67 associated with CTS is 27 days per year, i.e. longer than any other (except fractures) work

68 related disorder (Foley et al., 2007). Therefore, CTS is the most expensive musculoskeletal

69 disorder of the upper limb, whose estimated cost of medical care in the United States exceeds \$ 2

70 billion a year - mainly due to surgical procedures (Stapleton, 2006). Thus, high economic

71 (including surgical treatment) and social costs connected with CTS require exploration for cost-

72 effectiveness and effective (long-term) treatments for this neuropathy.

73 The authors of scientific reports, as well as clinicians (including the American Academy of

74 Neurology and the American Academy of Orthopaedic Surgeons), emphasise that conservative treatment should be used as first-line therapy, and only after the ineffectiveness of such treatment

76 should surgical treatment be considered (Gerritsen et al., 2002). Frequently, conservative CTS

77 treatment is based on physiotherapeutic management, in which procedures such as laser, 
78 ultrasound and manual therapy (including neurodynamic techniques) are applied (Giele, 2002).

79 Recently, two randomised controlled trials have shown that immediately after 10 weeks of

80 treatment (20 sessions), patients who received manual therapy based on neurodynamic

81 techniques had significant improvement immediately after therapy (Wolny \& Linek, 2019;

82 Wolny \& Linek, 2018). Wolny and Linek (Wolny \& Linek, 2019; Wolny \& Linek, 2018) showed

83 that neurodynamic techniques positively influenced outcomes, such as nerve conduction, pain,

84 subjective symptoms (SSS) and functional state (FSS) (Boston Carpal Tunnel Questionnaire -

85 BCTQ), and the perception of two-point discrimination (2PD). To date, Rozmaryn et al.

86 (Rozmaryn et al., 1998) and Bardak et al. (Bardak et al., 2009) revealed that after the application

87 of the therapeutic program, which consisted of manual therapy based on neurodynamic 88 techniques performed as an autotherapy program, a significant improvement in the clinical 89 condition in the long-term assessment of CTS patients was maintained. However, it should be 90 noted that in studies conducted by Rozmaryn et al. (Rozmaryn et al., 1998) the assessment was 91 retrospective and concerned only the subjective improvement of clinical condition and the 92 decrease in the number of surgical procedures performed. In the study by Bardak et al. (Bardak et 93 al., 2009) the group in which only neurodynamic techniques were used achieved the poorest 94 therapeutic effect. Akalin et al. (Akalin \& Peker, 2002) comparing groups of CTS patients 95 subject to the study showed that after the application of orthosis alone (group 1) and orthosis in 96 combination with manual therapy based on neurodynamic techniques (performed as an 97 autotherapy program) (group 2), the difference between the groups studied (in favour of group 2) 98 only concerned the pinch grip after eight weeks. Thus, there are some conflicting opinions 99 regarding the long-term effects of the therapy after the application of manual therapy based on 100 neurodynamic techniques in CTS patients. This may be due to a number of factors, such as the 
101 use of different therapeutic programs in which neurodynamic techniques were only one of the

102 elements of a comprehensive therapy, the use of neurodynamic techniques as autotherapy, 103 different duration of the therapy, the use of different research tools and the evaluation of other 104 parameters of the clinical status of CTS patients.

105 Manual therapy based on neurodynamic techniques aims to improve nerve slide in the carpal 106 tunnel, which is disturbed in CTS patients (Greening et al., 2001; Erel et al., 2003; Shacklock, 107 2005). It is even written that CTS is an "entrapment syndrome", which suggests a problem of the 108 nerve with its free slide in relation to the surrounding tissues. Restoration of the dynamic balance 109 between the relative motion of the nerve and the surrounding tissues may decrease the 110 pathological forces, mainly compressive, which in turn will improve the physiological function 111 of the nerve (Fernández-de-Las-Peñas et al., 2017). This improvement in neuromechanics after 112 the application of neurodynamic techniques may therefore further improve the physiology of the 113 nerve, even after the conclusion of the therapy. However, there is a possibility that the effects of 114 the therapy will persist only at the moment of continuous mechanical stimulation of the nerve, 115 and shortly after the therapy cycle (no further stimulation of the nerve), the nerve slide becomes 116 impaired again and CTS symptoms will reappear. Thus, to fully illustrate the effect of 117 neurodynamic techniques, it seems reasonable to assess the patient's condition not only 118 immediately after the therapy cycle but also during a longer observation period.

119 Hypothetically, it can be assumed that the therapeutic effect obtained directly after a 10120 week cycle of CTS therapy according to two recently published studies (Wolny \& Linek, 2019; 121 Wolny \& Linek, 2018) a) will be perpetual, b) will continue to improve as a result of restoring 122 the proper mechanics and physiology of the median nerve (and thus its possible regeneration) 123 and c) will deteriorate as a result of the lack of continuous mechanical stimulation of the nerve. 
124 From a therapeutic point of view, long-term effects seem to be more important (compared to the

125 effects immediately after the end of the therapy cycle), as they are the only ones that can

126 significantly improve the health of patients and really influence economic and social costs. Thus,

127 further patients` observation after treatment procedures seems reasonable and warranted.

128 Fernández-de-Las-Peñas et al. (Fernández-de-Las-Peñas et al., 2017) demonstrated that manual

129 therapy and surgery had similar effectiveness for improving self-reported function, symptom

130 severity, and pinch-tip grip force in CTS patients but manual therapy has been found to be less

131 costly than surgery in CTS treatment. Therefore, the objective of this study was to evaluate the

132 outcomes changes six months after manual therapy based only on the neurodynamic techniques

133 treatment of CTS patients. In some studies the follow-up 6 months period is considered as a

134 long-term (Dakowicz et al.,2011; Fernández-de-Las-Peñas et al., 2019)

135

136

137

138

139

140

141

142

143

144

145

146

147

148

\section{Materials \& Methods}

Ethics

The study was authorized by the Bioethics Committee for Scientific Studies at the Academy of Physical Education in Katowice on 08 March 2012 (Decision No. 7/2012), the annex on 28 February 2017 (No. KB/6/17). All study procedures were performed according to the Helsinki Declaration of Human Rights of 1975, modified in 1983. The clinical trial was registered at the Australian New Zealand Clinical Trials Registry (ANZCTR), number ACTRN12617000672358. All patients were informed about what the study would involve and told that they could withdraw at any stage without giving a reason. This study was conducted without a control group, as it is unethical to leave CTS patients without treatment for six months. Written informed consent was obtained from all participants. 


\section{Study Design}

150 This study was an observational study in which patients from two previously published 151 randomised clinical trials (Wolny \& Linek, 2019; Wolny \& Linek, 2018) were observed for six 152 months after their last treatment procedure. In both studies, manual therapy based on 153 neurodynamic techniques was compared to no treatment (Wolny \& Linek, 2019) and 'sham`

154 therapy (Wolny \& Linek, 2018) in CTS patients, and the outcomes (nerve conduction, pain, 155 symptom severity, functional status, 2PD, and muscle strength (MS) were collected and analysed 156 immediately after the last treatment. Patients who received manual therapy based on 157 neurodynamic techniques were then observed for six months after the conclusion of therapy, 158 when all mentioned outcomes were measured again. In the first (Wolny \& Linek, 2019) and 159 second (Wolny \& Linek, 2018) study, the sample size was calculated based on results from 10 160 and 20 participants, respectively. In both cases, the calculation of sample size was based on an 161 alpha of 0.05 and a statistical power of 0.8 . The study reported here was prepared in accordance 162 with CONSORT guidelines (when applicable).

163

164 165

\section{Participants}

The long-term observation are presented separately for CTS patients from the first study (group A (Wolny \& Linek, 2019)) and CTS patients from the second study (group B (Wolny \& Linek, 2018)) in such a way that the results can undergo intra-group and inter-group comparisons. Immediately after the therapy 58 CTS patients in group A and 78 CTS patients in group B were evaluated. A detailed scheme of the participants' flow is presented in Figure 1.Basic characteristics and biometric features of patients in both groups are presented in Table 1. Table 1 here 
172

173

174

175

176

177

178

179

180

181

182

183

184

185

186

187

188

189

190

192

193

191 The exclusion criteria were lack of consent, lack of cooperation from the patient, previous

Figure 1 here

(1)

\section{Diagnostic Criteria for CTS}

The CTS diagnosis was made by a physician on the basis of data collected from the interview, nerve conduction study (NCS), and clinical examinations. Based on the NCS, only participants who had diminished nerve conduction values $(<50 \mathrm{~m} / \mathrm{s})$ and increased motor latency $(>4 \mathrm{t}(\mathrm{ms}))$ were included. The clinical diagnosis of CTS was based on the criteria that Chang et al. (Chang et al., 2008) proposed:

1. Numbness and tingling in the area of the median nerve;

2. Night-timeparaesthesia;

3. PositivePhalen's test;

4. PositiveTinel'ssign;

5. Pain in the wrist area radiating to the shoulder.

According to these criteria, the diagnosis of CTS was based on the presence of two or more symptoms (Chang et al., 2008). conservative, surgical or pharmacological therapy, cervical radiculopathy, diabetes, rheumatoid disease, pregnancy, past trauma to the wrist, and muscular atrophy of the thenar eminence.

\section{Outcome Measures}


The NCS was performed in the same laboratory where the tests were performed immediately 196 after the therapy (Wolny \& Linek, 2019; Wolny \& Linek, 2018). All test procedures were 197 consistent with previous studies (Wolny \& Linek, 2019; Wolny \& Linek, 2018). Neuro-Mep 198 electrodiagnostic equipment was used to perform the examinations, using an antidromic method 199 with superficial electrodes. The temperature in the room where the test was performed was 24$20026^{\circ} \mathrm{C}$. Before examination, patients were acclimated for 10 to 15 minutes. The skin temperature 201 was measured by means of a surface thermometer and fluctuated between $32-34^{\circ} \mathrm{C}$. The 202 assessment of nerve conduction results was based on the same normative values recommended 203 by the laboratory where the following tests were performed: sensory conduction velocity $\geq 50$ $204 \mathrm{~m} / \mathrm{s}$, motor conduction velocity $\geq 50 \mathrm{~m} / \mathrm{s}$, and distal motor latency $\leq 4.0 \mathrm{t}(\mathrm{m} / \mathrm{s})$.

205 The pain was measured with the Numerical Pain Rating Scale (NPRS) (where "0" = no pain 206 and"10" = maximum pain) (Jensen et al. 1999). Patients were asked to report the greatest pain in 207 the CTS limb that they had felt during the last six months.

208 Assessment of the intensity of symptoms and disorders of hand functions was made with the 209 BCTQ (Levine et al., 1993). This questionnaire assessed the subjective symptoms reported by 210 the patient (SSS) and the functional state (FSS) of the patient. In patients with bilateral CTS, the 211 questionnaire was performed separately for each hand.

212 MS in both the cylindrical and pinch grip tests was evaluated using the Jamara 213 dynamometers according to the recommendations of the American Society of Hand Therapists 214 (Watanabe et al., 2005). During the test, the dynamometer was placed between the metacarpus 215 and through the fifth fingers (cylindrical grip) and between the thumb and the lateral surface of 216 the index finger (pinch grip). The values were in kilograms of strength $(\mathrm{kg})$. The measurement 
217 was done three times, and the mean value was added to the analysis (Wolny \& Linek, 2019; 218 Wolny \& Linek, 2018).

219 The examination of 2PD was performed using a standardized Dellon discriminator (Crosby $220 \&$ Dellon, 1989). The 2PD study used the procedure proposed by Wolny et al. (Wolny et al., 221 2017) The measurement was done three times, and the mean value was added to the analysis.

\section{Intervention}

223

Physiotherapy for both groups was based on neurodynamic techniques directed at the 224 median nerve. Both sliding and tensioning techniques were used. The following techniques were 225 used: one-direction proximal sliding mobilisation, one-direction distal sliding mobilisation, one226 direction proximal tensioning mobilisation and one-direction distal tensioning mobilisation. The 227 standard protocol consisted of three series of 60 repetitions of sliding and tensioning 228 neurodynamic techniques separated by inter-series intervals of $15 \mathrm{~s}$, twice a week for 20 229 sessions. A detailed description of the techniques used (including photos) can be found 230 elsewhere (Wolny \& Linek, 2019; Wolny \& Linek, 2018).

231

232 233 234 235 236 237 238 239

\section{Statistical analysis}

Analysis of the collected data was performed using the Statistica 13.1 software package. Data collected immediately after 10 weeks of treatment was compared with data collected after six months of follow-up by dependent (comparisons inside groups A and B) and independent ttests (comparisons between groups A and B). For nominal data, the Chi-Square $\left(\chi^{2}\right)$ test was used. The critical p-level was set to 0.05 .

\section{Results}


Sensory conduction velocity, motor conduction velocity and motor latency in both groups A

241 and $\mathrm{B}$ were not subject to statistically significant changes six months after the conclusion of 242 therapy. In group A differences in sensory conduction velocity, motor conduction velocity and 243 motor latency was $1.7(95 \%$ CI, 2.19 - 5.73), 2.1 (95\% CI, 1.11 - 5.25) and 0.08 (95\% CI, 0.15 244 0.31) respectively. In group B differences in sensory conduction velocity, motor conduction 245 velocity and motor latency was 2.1 (95\% CI, $1.25-5.27), 1.3$ (95\% CI, $0.49-3.13)$ and 0.07 $246(95 \%$ CI, $0.14-0.27)$ respectively. In both analysed groups, there were significant differences in 247 pain between the results obtained immediately after the end of the therapy and after six months 248 of observation. In groups A and B, pain reduction was $0.34(95 \% \mathrm{CI}, 0.09-0.39)$ and $0.34(95 \%$ 249 CI, $0.18-0.51$ ), respectively. In the assessment of subjective symptoms, the comparison of 250 results obtained immediately after the end of therapy and six months later in group A did not 251 show statistically significant differences compared to group B. These differences occurred only 252 in group B where pain reduction was 0.23 (95\% CI, $0.13-0.32)$. In the assessment of function, 253 the comparison of results obtained immediately after the end of therapy and six months later in 254 both groups did not show statistically significant differences. MS in both examined grips (i.e., 255 cylindrical and pinch) improved in both examined groups six months after the conclusion of the 256 therapy. In group A, the strength of the pinch and cylindrical grip tests improved by $0.53 \mathrm{~kg}$ 257 (95\% CI, $0.26-0.81)$ and $1.1 \mathrm{~kg}(95 \% \mathrm{CI}, 0.39-1.84)$, respectively. In group B, the average 258 improvement was $0.43 \mathrm{~kg}(95 \% \mathrm{CI}, 0.13$ - 0.84) for the pinch grip and $0.8 \mathrm{~kg}(95 \% \mathrm{CI}, 0.24-$ 259 1.61) for the cylindrical grip. The 2PD sensation did not show statistically significant changes in 260 group B, comparing the results immediately after the conclusion of the therapy and 6 months 261 later. In group A, the discriminatory sensation was not studied. Detailed data are presented in 
262 Table 2. Additionally, the comparative analysis carried out between groups A and B did not 263 show statistically significant differences (in all cases $\mathrm{P}>0.05$ ).

\section{Discussion}

266 The primary objective of this study was to evaluate the long-term effects of manual therapy 267 based on the application of neurodynamic techniques in CTS patients. The present study 268 identified that both groups were significant differences in pain and MS at follow-up 6 months. 269 The assessment of subjective symptoms of group B showed significantly different at follow-up 6 270 months. However, comparable outcomes of sensory conduction velocity, motor conduction 271 velocity, motor latency and assessment of cunction were disclosed between both groups. 272 Therefore, it can be concluded that manual therapy based on neurodynamic techniques has 273 beneficial effects in the physiotherapy of patients with mild and moderate CTS not only in the 274 evaluation immediately after therapy but also in the long-term evaluation (six months).

275 The maintenance of different parameters of nerve conduction, function and 2PD sense at the 276 same level indicates a beneficial therapeutic effect. However, those parameters (sensory 277 conduction velocity, motor conduction velocity, distal motor latency, functional status, and 2PD 278 sense) did not reach normative values after 20 therapeutic sessions, which may suggest that: a) 279 the therapy (nerve stimulation) did not last long enough and b) the therapy applied reduced, but 280 did not (completely) remove, the adverse changes occurring in the nerve. The six-month 281 observation showed that patients undergoing the given therapy experienced further significant 282 pain reduction, which may result from the improvement of nerve mechanics immediately after 283 the therapy. The pain before the beginning of the therapy lasted for many months, so it could 284 already have its central representation, as suggested by some authors (Barr et al., 2004). 
285 Therefore, a longer observation period was necessary for the change (reduction) of pain. A 286 significant increase in MS (despite the lack of further therapy) may be related to the pain 287 reduction achieved. Tamburin et al. (Tamburin et al. 2008) demonstrated that pain is a factor 288 contributing to weakening MS. Reduction of pain probably resulted in more frequent use of the 289 hand (during various daily activities), which naturally contributed to an increase in the strength 290 of the muscles releasing both the cylindrical and pinch grip tests.

291 A number of authors evaluated the long-term effects of manual therapy based on the 292 application of neurodynamic techniques in CTS patients. Rozmaryn et al. (Rozmaryn et al., 293 1998) in a clinical and control retrospective study in which 197 CTS patients (divided into two 294 groups) were examined, evaluated the therapeutic program that included orthosis, non-steroidal 295 anti-inflammatory drugs and steroid injections, as well as variable temperature baths. In the 296 experimental group, CTS patients were additionally instructed on how to perform neurodynamic 297 techniques on their own, as an autotherapy program. After an average period of 23 months, 298 $70.2 \%$ of the subjects declared positive effects of the therapy, and only $19.2 \%$ reported that the symptoms of CTS remained unchanged. In their conclusions, the authors emphasised that the use 300 of the therapeutic program presented above may significantly reduce the number of patients 301 subject to surgical treatment. On the other hand, Bardak et al. (Bardak et al., 2009) evaluated 11 302 CTS patients, who were divided into three groups (group 1 - therapy was based on steroid 303 injections and orthosis; group 2 - therapy was based on steroid injections, orthosis and 304 neurodynamic techniques as an autotherapy program; and group 3 - only neurodynamic 305 techniques as an autotherapy program), and therapeutic effects were evaluated 11 months after 306 the conclusion of therapy. Significant functional improvement and symptom reduction were 307 achieved in all groups, although the results in the group where only neurodynamic techniques 
308 were used, were significantly weaker. In another study, Akalin et al. (Akalin et al., 2002)

309 evaluated 28 CTS patients, who were divided into two groups. In both groups, the therapy

310 consisted of putting on an orthosis overnight and wearing it as long as possible during the day

311 (for four weeks). Additionally, in the experimental group, patients were instructed how to

312 perform neurodynamic techniques on their own, as an autotherapy program. In the final

313 evaluation, after eight weeks of therapy, a statistically significant improvement of all parameters

314 was achieved in both groups. In the experimental group (in which neurodynamic techniques were

315 used), a significant difference from the group wearing just the orthosis occurred only in the

316 assessment of the pinch grip in favour of the experimental group.

317 Contrary to the present study, the results of the studies presented in the above paragraph do

318 not clearly indicate beneficial long-term therapeutic effects of the application of neurodynamic

319 techniques in CTS patients. This is probably due to the different methods of therapeutic

320 management since neurodynamic techniques were only an additional element of the therapeutic

321 program and were always used as an autotherapy program, which makes it difficult (impossible)

322 to constantly control the regularity and correctness of the mobilisations performed. This study (as

323 well as recently published work by Wolny and Linek (Wolny \& Linek, 2019; Wolny \& Linek,

324 2018), shows that neurodynamic techniques performed by a qualified physiotherapist have a

325 positive therapeutic effect not only immediately after the therapy but also during the six-month

326 observation period. In assessing the effectiveness of any manual therapy (including

327 neurodynamic techniques), the manner in which the therapy is conducted is crucial, as only a 328 trained person can guarantee the appropriate technique, control and regularity of the conducted 329 therapy. In every autotherapy (including neurodynamic techniques), it is difficult to control the 
330 variables that are unquestionable in the methodology of scientific research. Thus, the assessment

331 of the effectiveness of neurodynamic techniques used in the form of autotherapy is questionable.

332 So far, the literature has lacked studies evaluating the long-term effects of manual therapy

333 based on neurodynamic techniques, which would be the only form of therapy in CTS patients.

334 Therefore, the conducted studies are the first to present beneficial effects of manual therapy

335 based on neurodynamic techniques in the evaluation of long-term effects of physiotherapy on

336 CTS patients. The high value of such studies is the evaluation of both objective indicators, such

337 as nerve conduction, 2PD sense, MS and subjective sensations of CTS in patients related to pain

338 reduction, symptom severity reduction and improvement of function. The results of the research

339 allow us to conclude that manual therapy based on neurodynamic techniques has beneficial

340 therapeutic effects in the conservative treatment of mild and moderate forms of CTS both in the

341 short-term evaluation (Wolny \& Linek, 2019; Wolny \& Linek, 2018) and in the evaluation of

342 long-term therapeutic effects.

\section{Limitations}

344 The lack of a control group is a major flaw of the present study because important other

345 variables like spontaneous recovery, Hawthorne effects or placebo effects would contribute to

346 the outcomes observed. Thus, the lack of a control group means that we cannot estimate true

347 therapeutic effects in isolation from other effects. For ethical reasons, we were unable to leave

348 patients without any therapy for such a long period of time. However, we believe that after

349 successful treatment the patients should be further observed how they outcomes are changing in

350 long term. From a therapeutic point of view, distant therapeutic results seem to be more

351 important (compared to the effects immediately after the end of the therapy cycle), as they are 
352 the only ones that can significantly improve the general health of patients and really influence

353 economic and social costs.

354

355

356

357

358

359

360

361

362

363

364

365

366

367

368

369

370

371

372

373

374

375

376

377

378

379

\section{Conclusions}

Six months after the last session of manual therapy based on neurodynamic techniques parameters of nerve conduction(sensory conduction velocity, motor conduction velocity and distal motor latency) and functional state were at a similar level to the results gained immediately after therapy. Within six months after the application of neurodynamic techniques, further pain reduction and improvement in the strength of the muscles engaged during both the pinch and cylindrical grip tests were observed in CTS patients.

\section{Acknowledgements}

Lack

\section{References}

1. Aroori S, Spence RA. 2008. Carpal tunnel syndrome. Ulster Med J.77(1):6-17.

2. Biernawska J, Niemczyk A, Pierzchała K. 2005. Contribution of occupational and nonoccupational factors In the pathogenesis of car pal tunel syndrome..Med Pr.56(2):131-137.

3. Wolny T, Saulicz E, Linek P, Myśliwiec A. 2015. Kinesthesia of force and motion and the tactile discrimination in patients with a mild form of carpal tunnel syndrome.Phys Med. Rehab Kuror.25(2):101-107.

4. Wolny T, Saulicz E, Linek P, Myśliwiec A. 2016. Two-point discrimination and kinesthetic 
sense disorders in productive age individuals with carpal tunnel syndrome. J Occup Health. 58(3):289-296.

382

5. Chang WD, Wu JH, Jiang JA, Yeh CY, Tsai CT. 2008. Carpal tunnel syndrome treated with a diode laser: a controlled treatment of the transverse carpal ligament. Photomed Laser Surg. 26(6):551-557.

6. Wolny T, Saulicz E, Linek P. 2017. Overall health status in patients with mild to moderate carpal tunnel syndrome: a case-control study. J Hand Ther.30(3):293-298.

7. Thiese MS, Gerr F, Hegmann KT, Harris-Adamson C, Dale AM, Evanoff B, Eisen EA, Kapellusch J, Garg A, Burt S, Bao S, Silverstein B, Merlino L, Rempel D. 2014. Effects of varying case definition on carpal tunnel syndrome prevalence estimates in a pooled cohort. Arch Phys Med Rehabil.95:2320-6.

391

8. Thorne CH. 2007. Grabb and Smith's Plastic Surgery. Philadelphia: Lippincott Williams \& 392 Wilkins.

393

9. Newington L, Harris EC, Walker-Bone K. 2015. Carpal tunnel syndrome and work. Best Pract Res Clin Rheumatol.29:440-53.

10. Foley M, Silverstein B, Polissar N. 2007. The economic burden of carpal tunnel syndrome: long-term earnings of CTS claimants in Washington State. Am J Ind Med.50(3):155-72.

11. Stapleton M. Occupation and carpal tunnel syndrome.2006. Anz Journal of Surgery.76(6): 398 494-96.

12. Gerritsen AA, de Vet HC, Scholten RJ, Bertelsmann FW, de Krom MC, Bouter LM.2002. Splinting vs surgery in the treatment of carpal tunnel syndrome: a randomized controlled trial. JAMA.288(10):1245-51.

402 13. Giele H. Evidence-based treatment of carpal tunnel syndrome. 2001. CurrOrthop. 
404 14. Wolny T, Linek P. 2019. Is manual therapy based on neurodynamic techniques effective in 405 the treatment of carpal tunnel syndrome? A randomizedcontrolled trial. Clin Rehabil. $406 \quad 33(5): 957-58$.

407 15. Wolny T, Linek P. 2018. Neurodynamic techniques versus `sham` therapy in the treatment 408 of carpal tunnel syndrome: a randomized placebo-controlled trial. Arch Phys Med. Rehabil. $40999(5): 843-54$.

410 16. Rozmaryn LM, Dovell S, Rothman ER, Gorman K, Olvey KM, Bartko JJ. 1998. Nerve and 411 tendon gliding exercises and the conservative management of carpal tunnel syndrome. $J$ $412 \quad$ Hand Ther.11(3):171-79.

413 17. Bardak AN, Alp M, Erhan B, Paker N, Kaya B, Önal AE. 2009. Evaluation of the clinical 414 efficacy of conservative treatment in the management of carpal tunnel. AdvTher. 26(1):107$415 \quad 16$.

416 18. Akalin E, El O, Peker O. 2002. Treatment of carpal tunnel syndrome with nerve and tendon 417 gliding exercises. Am J Phys Med Rehabil. 81(2):108-13.

418 Hough AD, Moore AP, Jones MP. 2000. Peripheral nerve motion measurement with spectral 419 Doppler sonography: a reliability study. J Hand Surg Br. 25(6):585-89.

420 19. Greening J, Lynn B, Leary R, Warren L, O'Higgins P, Hall-Craggs M. 2001. The use of 421 ultrasound imaging to demonstrate reduced movement of the median nerve during wrist 422 flexion in patients with non-specific arm pain. J Hand Surg Br.26(5):401-406.

423 20. Erel E, Dilley A, Greening J, Morris V, Cohen B, Lynn B. 2003. Longitudinal sliding of the 424 median nerve in patients with carpal tunnel syndrome. J Hand Surg Br.28(5):439-443. 425 21. Shacklock M. Clinical Neurodynamics. 2005. Oxford: Butterworth-Heinemann. 
426

427

428

429

430

431

432

433

434

435

436

437

438

439

440

441

442

443

444

445

446

447

448

22. Fernández-de-Las-Peñas C, Cleland J, Palacios-Ceña M, Fuensalida-Novo S, Pareja JA, Alonso-Blanco C. 2017. The Effectiveness of Manual Therapy Versus Surgery on Selfreported Function, Cervical Range of Motion, and Pinch Grip Force in Carpal Tunnel Syndrome: A Randomized Clinical Trial. J Orthop Sports PhysTher. 47(3):151-161.

23. Fernández-de-Las-Peñas C, Ortega-Santiago R, Díaz HF, Salom-Moreno J, Cleland JA, Pareja JA, Arias-BuríaJL. 2019. Cost-Effectiveness Evaluation of Manual Physical Therapy Versus Surgery for Carpal Tunnel Syndrome: Evidence From a Randomized Clinical Trial. J Orthop Sports PhysTher. 49(2):55-63.

24. Dakowicz A, Kuryliszyn-Moskal A, Kosztyła-Hojna B, Moskal D, Latosiewicz R. 2011. Comparison of the long-term effectiveness of physiotherapy programs with low-level laser therapy and pulsed magnetic field in patients with carpal tunnel syndrome. Adv Med Sci.56(2):270-4.

25. Fernández-de-Las-Peñas C, de-la-Llave-Rincón AI, Cescon C, Barbero M, Arias-Buría JL, Falla D. 2019. Influence of Clinical, Psychological, and Psychophysical Variables on Long-term Treatment Outcomes in Carpal Tunnel Syndrome: Evidence From a Randomized Clinical Trial. Pain Pract.19(6):644-655.

26. Jensen MP, Turner JA, Romano JM, Fisher LD.1999. Comparative reliability and validity of chronic pain intensity measures. Pain.83(2):157-62.

27. Levine DW, Simmons BP, Koris MJ, Daltroy LH, Hohl GG, Fossel AH, Katz JN. 1993. A self-administered questionnaire for the assessment of severity of symptoms and functional status in carpal tunnel syndrome. J Bone Joint Surg Am.75(11):1585-92.

28. Watanabe T, Owashi K, Kanauchi Y, Mura N, Takahara M, Ogino T. 2005. The short-term reliability of grip strength measurement and the effects of posture and grip span. $J$ Hand 
449 Surg Am. 30(3):603-09.

450 29. Crosby PM, Dellon AL. 1989. Comparison of two-point discrimination testing devices. $451 \quad$ Micro Surg.10(2):134-37.

452 30. Wolny T, Linek P, Michalski P. 2017. Inter-rater reliability of two point discrimination in 453 acute stroke patients. Neurorehabilitation.41(1):127-34.

454 31. Barr AE, Barbe MF, Clark BD.2004. Work-related musculoskeletal disorders of the hand 455 and wrist: epidemiology, pathophysiology, and sensorimotor changes. J Orthop Sports 456 PhysTher.34(10):610-27.

457 32. Tamburin S, Cacciatori C, Marani S, Zanette G.2008. Pain and motor function in carpal 458 tunnel syndrome: a clinical, neurophysiological and psychophysical study. J Neurol. $459 \quad 255(11): 1636-43$.

460 


\section{Table $\mathbf{1}$ (on next page)}

Basic characteristics of the examined population.

${ }^{1}$-Data immediately after 10 weeks of treatment from published articles (Group A - Wolny and Linek (Wolny \& Linek, 2019); Group B - Wolny and Linek (Wolny \& Linek, 2018)); ${ }^{2}$ - 't'test for dependent variables; $\mathrm{n}$ - number of participants; NA - not applicable; CTS - carpal tunnel syndrome; $\mathrm{BMI}$ — body mass index 
Table 1. Basic characteristics of the examined population.

\begin{tabular}{|c|c|c|c|c|c|c|}
\hline \multirow{2}{*}{ Characteristics } & \multicolumn{3}{|c|}{ Group A $(n=46)$} & \multicolumn{3}{|c|}{ Group B $(n=61)$} \\
\hline & Baseline $^{1}$ & $\begin{array}{c}6 \text { months } \\
\text { later }\end{array}$ & $\begin{array}{c}\text { P- } \\
\text { value }^{2}\end{array}$ & Baseline $^{1}$ & $\begin{array}{c}6 \text { months } \\
\text { later }\end{array}$ & $\begin{array}{c}\text { P- } \\
\text { value }^{2}\end{array}$ \\
\hline Women (\%) & $40(87)$ & $40(87)$ & NA & $40(87)$ & $40(87)$ & NA \\
\hline Age (SD) year & $54.6(8.4)$ & $54.7(8.3)$ & 0.93 & $54.1(9.3)$ & $54.2(9.3)$ & 0.93 \\
\hline $\begin{array}{c}\text { Body mass (SD) } \\
\mathrm{kg}\end{array}$ & $70.4(11.1)$ & $70.5(10.8)$ & 0.96 & $\begin{array}{c}70.4 \\
(11.1)\end{array}$ & $\begin{array}{c}70.5 \\
(10.8)\end{array}$ & 0.96 \\
\hline Height (SD) $\mathrm{cm}$ & $\begin{array}{l}163.4 \\
(6.88)\end{array}$ & $163.6(6.86)$ & 0.89 & $\begin{array}{l}163.5 \\
(6.5)\end{array}$ & $\begin{array}{l}163.4 \\
(6.6)\end{array}$ & 0.98 \\
\hline $\begin{array}{c}\mathrm{BMI}(\mathrm{SD}) \\
\mathrm{kg} / \mathrm{m}^{2}\end{array}$ & $26.6(4.17)$ & $26.7(4.12)$ & 0.90 & $\begin{array}{r}26.6 \\
(4.71)\end{array}$ & $\begin{array}{c}26.8 \\
(4.57)\end{array}$ & 0.92 \\
\hline
\end{tabular}

\section{CTS symptoms:}

-Unilateral $(\%)$

$34(74)$

NA

45 (74)

$45(74)$

NA

-Bilateral (\%)

$12(26)$

$12(26)$

NA $16(26)$

$16(26)$

NA

2

3

4

5

6

1 -Data immediately after 10 weeks of treatment from published articles (Group A - Wolny and Linek (Wolny \& Linek, 2019); Group B - Wolny and Linek(Wolny \& Linek, 2018)); ${ }^{2}$ — ' $\mathrm{t}$ '-test for dependent variables; $\mathrm{n}$ - number of participants; NA — not applicable; CTS — carpal tunnel syndrome; BMI — body mass index 


\section{Table 2 (on next page)}

Outcomes measured in the examined population.

${ }^{1}$-Data immediately after 10 weeks of treatment from published articles (Group A -Wolny and Linek (Wolny \& Linek, 2019); Group B -Wolny and Linek (Wolny \& Linek, 2018)); ${ }^{2}$ ' $\mathrm{t}$ '-test for dependent variables; *statistically significant difference; SCV - sensory conduction velocity; MCV - motor conduction velocity; MT - motor latency; NPRS -Numerical Pain Rating Scale; BCTQ -Boston Carpal Tunnel Questionnaire; SSS - Symptom Severity Scale; FSS - Functional Status Scale; MS CG - Muscle Strength Cylindrical Grip; MS PG - Muscle Strength Pincer Grip; 2PD - Two - Point Discrimination Sense; FI, FII, FIII — Finger I, II, III; NA - not applicable. 
1 Table 2. Outcomes measured in the examined population.

\begin{tabular}{|c|c|c|c|c|c|c|}
\hline \multirow[t]{2}{*}{ Characteristics } & \multicolumn{3}{|c|}{ Group A $(n=46)$} & \multicolumn{3}{|c|}{ Group B $(n=61)$} \\
\hline & Baseline $^{1}$ & $\begin{array}{c}6 \text { months } \\
\text { later }\end{array}$ & $\begin{array}{c}\text { P- value }{ }^{2}, \\
95 \% \text { CI }\end{array}$ & Baseline $^{1}$ & $\begin{array}{c}6 \text { months } \\
\text { later }\end{array}$ & $\begin{array}{c}\text { P- value }{ }^{2} \text {, } \\
95 \% \mathrm{CI}\end{array}$ \\
\hline $\mathrm{SCV}(\mathrm{SD}) \mathrm{m} / \mathrm{s}$ & $\begin{array}{c}37.8 \\
(10.9)\end{array}$ & $\begin{array}{c}36.1 \\
(10.3)\end{array}$ & $\begin{array}{c}0.37 \\
(2.19- \\
5.73)\end{array}$ & $\begin{array}{c}36.5 \\
(10.3)\end{array}$ & $\begin{array}{c}34.4 \\
(10.7)\end{array}$ & $\begin{array}{c}0.22 \\
(1.25- \\
5.27)\end{array}$ \\
\hline $\mathrm{MCV}(\mathrm{SD} \mathrm{m} / \mathrm{s}$ & $\begin{array}{c}55.9 \\
(7.21)\end{array}$ & $\begin{array}{c}53.8 \\
(9.75)\end{array}$ & $\begin{array}{c}0.21 \\
(1.11- \\
5.25)\end{array}$ & $\begin{array}{c}55.7 \\
(6.36)\end{array}$ & $\begin{array}{c}54.4 \\
(5.29)\end{array}$ & $\begin{array}{c}0.15 \\
(0.49- \\
3.13)\end{array}$ \\
\hline $\mathrm{MT}(\mathrm{SD}) \mathrm{t}(\mathrm{ms})$ & $\begin{array}{c}4.53 \\
(0.67)\end{array}$ & $\begin{array}{c}4.45 \\
(0.57)\end{array}$ & $\begin{array}{c}0.53 \\
(0.15- \\
0.31)\end{array}$ & $\begin{array}{r}4.46 \\
(0.72)\end{array}$ & $\begin{array}{l}4.39 \\
(0.63)\end{array}$ & $\begin{array}{c}0.52 \\
(0.14- \\
0.27)\end{array}$ \\
\hline $\begin{array}{c}\text { NPRS }(\mathrm{SD})(0- \\
10)\end{array}$ & $\begin{array}{c}1.38 \\
(1.04)\end{array}$ & $\begin{array}{c}1.04 \\
(0.57)\end{array}$ & $\begin{array}{c}0.00^{*} \\
(0.09- \\
0.39)\end{array}$ & $\begin{array}{c}1.41 \\
(1.04)\end{array}$ & $\begin{array}{l}1.07 \\
(0.77)\end{array}$ & $\begin{array}{c}0.00^{*} \\
(0.18- \\
0.51)\end{array}$ \\
\hline $\begin{array}{c}\text { BCTQ-SSS } \\
\text { (SD) }\end{array}$ & $\begin{array}{c}1.81 \\
(0.46)\end{array}$ & $\begin{array}{c}1.73 \\
(0.45)\end{array}$ & $\begin{array}{c}0.31 \\
(0.08- \\
0.25)\end{array}$ & $\begin{array}{c}1.71 \\
(0.45)\end{array}$ & $\begin{array}{c}1.48 \\
(0.35)\end{array}$ & $\begin{array}{c}0.00^{*} \\
(0.13- \\
0.32)\end{array}$ \\
\hline $\begin{array}{c}\text { BCTQ-FSS } \\
\text { (SD) }\end{array}$ & $\begin{array}{l}2.02 \\
(0.68)\end{array}$ & $\begin{array}{c}1.81 \\
(0.55)\end{array}$ & $\begin{array}{c}0.06 \\
(0.01- \\
0.44)\end{array}$ & $\begin{array}{l}1.95 \\
(0.61)\end{array}$ & $\begin{array}{c}1.82 \\
(0.49)\end{array}$ & $\begin{array}{c}0.15 \\
(0.04- \\
0.31)\end{array}$ \\
\hline MS CG (SD) kg & 28.4 & 29.5 & $0.00^{*}$ & 27.3 & 28.1 & $0.00^{*}$ \\
\hline
\end{tabular}




\begin{tabular}{|c|c|c|c|c|c|c|}
\hline & $(6.32)$ & $(5.89)$ & $\begin{array}{c}(0.39- \\
1.84)\end{array}$ & $(6.22)$ & $(5.33)$ & $\begin{array}{c}(0.24- \\
1.61)\end{array}$ \\
\hline MS PG (SD) kg & $\begin{array}{c}7.92 \\
(1.46)\end{array}$ & $\begin{array}{c}8.45 \\
(1.61)\end{array}$ & $\begin{array}{c}0.00^{*} \\
(0.26- \\
0.81)\end{array}$ & $\begin{array}{c}7.88 \\
(1.55)\end{array}$ & $\begin{array}{c}8.31 \\
(1.34)\end{array}$ & $\begin{array}{c}0.00^{*} \\
(0.13- \\
0.84)\end{array}$ \\
\hline 2PD FI (SD) & & & & $\begin{array}{c}4.04 \\
(0.86)\end{array}$ & $\begin{array}{c}3.81 \\
(0.69)\end{array}$ & $\begin{array}{c}0.14 \\
(0.01- \\
0.47)\end{array}$ \\
\hline 2PD FII (SD) & & NA & & $\begin{array}{c}3.43 \\
(0.82)\end{array}$ & $\begin{array}{c}3.21 \\
(0.75)\end{array}$ & $\begin{array}{c}0.07 \\
(0.02- \\
0.46)\end{array}$ \\
\hline 2PD FIII (SD) & & & & $\begin{array}{c}3.38 \\
(0.88)\end{array}$ & $\begin{array}{c}3.45 \\
(0.91)\end{array}$ & $\begin{array}{c}0.84 \\
(0.84- \\
0.69)\end{array}$ \\
\hline
\end{tabular}

\footnotetext{
1 -Data immediately after 10weeks of treatment from published articles (Group A Wolny and Linek (Wolny \& Linek, 2019); Group B - Wolny and Linek (Wolny \& Linek, 2018)); ${ }^{2}$ — ' $\mathrm{t}$ '— test for dependent variables; *statistically significant difference; $\mathrm{SCV}$ - sensory conduction velocity; MCV — motor conduction velocity; MT — motor latency; NPRS -Numerical Pain Rating Scale; BCTQ —Boston Carpal Tunnel Questionnaire; SSS — Symptom Severity Scale; FSS — Functional Status Scale; MS CG - Muscle Strength Cylindrical Grip; MS PG - Muscle Strength Pincer Grip; 2PD - Two - Point Discrimination Sense; FI, FII, FIII - Finger I, II, III; NA — not
} applicable. 


\section{Figure 1}

Flow diagram.

\begin{tabular}{|c|c|c|}
\hline $\begin{array}{l}\text { Group } \mathbf{A}^{\mathbf{1 4}} \\
\text { Allocated to observation }(\mathrm{n}=58)\end{array}$ & & $\begin{array}{l}\text { Group } \mathbf{B}^{15} \\
\text { Allocated to observation }(\mathrm{n}=78)\end{array}$ \\
\hline & \multirow[t]{2}{*}{ Follow-Up } & \\
\hline $\begin{array}{l}\text { Lost to follow-up (lack of final } \\
\text { results of the nerve conduction) } \\
(\mathrm{n}=5) \text {, no contact with the subject } \\
\qquad(\mathrm{n}=7)\end{array}$ & & $\begin{array}{l}\text { Lost to follow-up (lack of final } \\
\text { results of the nerve conduction) } \\
(\mathrm{n}=7) \text {, another steroid treatment } \\
(\mathrm{n}=2) \text {, no contact with the subject } \\
(\mathrm{n}=8)\end{array}$ \\
\hline & \multirow[t]{2}{*}{ Analysis } & \\
\hline Analyzed $(\mathrm{n}=46)$ & & Analyzed $(n=61)$ \\
\hline
\end{tabular}

